\title{
Investigation of the migration of triclabendazole residues to milk products manufactured from bovine milk, and stability therein, following lactating cow treatment
}

\author{
C. Power, ${ }^{*} †$ M. Danaher, $\ddagger$ R. Sayers,§ B. O’Brien,\# C. Clancy, ${ }^{*}$ A. Furey, $†$ and K. Jordan*1 \\ ${ }^{*}$ Food Safety Department, Teagasc Food Research Centre, Fermoy, Co. Cork, Ireland \\ †Team Elucidate, Department of Chemistry, Cork Institute of Technology, Bishopstown, Cork, Ireland \\ ¥Food Safety Department, Teagasc Food Research Centre, Ashtown, Dublin 15, Ireland \\ $\S$ Animal and Bioscience Research Department, and \\ \#Livestock Systems Department, Animal and Grassland Research and Innovation Centre, Teagasc, Moorepark, Fermoy, Co. Cork, Ireland
}

\begin{abstract}
Triclabendazole (TCB) is a flukicide used in the treatment of liver fluke in cattle; however, its use is currently prohibited in lactating dairy cows. In this study, following administration of $10 \%$ Fasinex (triclabendazole, Novartis Animal Health UK Ltd., Camberley, UK) the milk of 6 animals was used to manufacture dairy products, to ascertain if TCB residues in milk migrate into dairy products. The detection limit of the ultra-high-performance liquid chromatography-tandem mass spectrometry method used was $0.67 \mu \mathrm{g} / \mathrm{kg}$. The highest concentrations of TCB residue measured, within the individual cow milk yield, was 1,529 \pm 244 $\mu \mathrm{g} / \mathrm{kg}(\mathrm{n}=6)$, on $\mathrm{d} 2$ posttreatment. Days 2 and 23 posttreatment represented high and low residue concentrations, respectively. At each of these 2 time points, the milk was pooled into 2 independent aliquots and refrigerated. Milk products, including cheese, butter, and skim milk powder were manufactured using pasteurized and unpasteurized milk from each aliquot. The results for high residue milks demonstrated that TCB residues concentrated in the cheese by a factor of 5 (5,372 vs. $918 \mu \mathrm{g} / \mathrm{kg}$ for cheese vs. milk) compared with the starting milk. Residue concentrations are the sum of TCB and its metabolites, expressed as keto-TCB. Residues were concentrated in the butter by a factor of 9 (9,177 vs. $1,082 \mu \mathrm{g} / \mathrm{kg}$ for butter vs. milk) compared with the starting milk. For milk, which was separated to skim milk and cream fractions, the residues were concentrated in the cream. Once skim milk powder was manufactured from the skim milk fraction, the residue in powder was concentrated 15 -fold compared with the starting skim milk (7,252 vs. $423 \mu \mathrm{g} / \mathrm{kg}$ for powder vs. skim milk), despite the high temperature $\left(185^{\circ} \mathrm{C}\right)$ required during powder manufacture. For products
\end{abstract}

Received May 10, 2013.

Accepted June 29, 2013.

${ }^{1}$ Corresponding author: kieran.jordan@teagasc.ie manufactured from milk with low residue concentrations at d 23 posttreatment, TCB residues were detected in butter, cheese, and skim milk powder, even though there was no detectable residue in the milk used to manufacture these products. Triclabendazole residues were concentrated in some milk products (despite manufacturing treatments), exceeding residue levels in the starting milk and, depending on the storage conditions, may be relatively stable over time.

Key words: triclabendazole, residue, dairy product, flukicide

\section{INTRODUCTION}

Triclabendazole (TCB) belongs to the benzimidazole drug class and is widely used in human and veterinary medicine for the treatment and control of liver fluke (Fasciola hepatica, class Trematoda) infections (Alvarez et al., 2009). It has been widely used as a flukicide drug for over $20 \mathrm{yr}$ (Flanagan et al., 2011) due to its broad spectrum of activity against liver fluke from the earliest stage of infection onward (Brennan et al., 2007; McCann et al., 2010; Olaechea et al., 2011).

The importance of controlling liver fluke is apparent from the health issues and economic losses caused in food-producing animals (Knubben-Schweizer et al., 2010; Animal Health Ireland, 2011). Animals carrying the liverfluke parasite can suffer reduced weight gain (Knubben-Schweizer et al., 2010; O'Brien et al., 2010), weight loss, reductions in milk yield, lower productivity, and suboptimal fertility; in some species, the effects can be fatal (Sangster, 2001; Mezo et al., 2008). As a result, flukicides are normally administered as prophylactic doses to control fluke infestations in extensively reared animals such as dairy cows and sheep (Moreno et al., 2005; Rahman and Samad, 2010; Whelan et al., 2010). The use of flukicides in dairy cows can result in undesirable residues in milk and dairy products, which can affect food safety (Imperiale et al., 2011; Power et al., 
2012). Therefore, most flukicides, including products containing TCB, are not recommended for administration to dairy cows during lactation. The most common and practical time to treat dairy cows for fluke is during the dry period, when the animals are not producing milk, which is typically the 60-d period between drying off and calving (Gulay, 2004).

Until recently, albendazole and oxyclozanide were the only flukicides licensed for the treatment of dairy cows, but these drugs demonstrate activity only against adult stages of liver fluke. Products containing clorsulon or other broad-spectrum flukicides, such as closantel, nitroxynil, rafoxanide, or TCB, were prohibited from use in Irish dairy cows during lactating and dry periods (O'Brien et al., 2010). Recently, a TCB-containing product (Fasinex 240, 24\% wt/vol oral suspension; Novartis Animal Health UK Ltd., Camberley, UK) was licensed for use. This product cannot be used in lactating dairy cows but can be administered to pregnant animals under certain conditions. One such condition dictates that the treatment be given $35 \mathrm{~d}$ before calving, and that only milk taken from the cow at a time greater than $48 \mathrm{~h}$ postcalving can then be used for human consumption (Irish Medicine Board, 2012).

To prevent unsafe levels of these residues from entering the human food chain, and in the interest of public health, maximum residue limits (MRL) are set by the European Medicines Agency. The MRL is the maximum concentration of a veterinary drug residue legally permissible in food (European Commission, 2009, 2010). Establishment of an MRL is important because it enables the setting of an appropriate withdrawal period for a particular medicine. Then, once the level of residue in a foodstuff is lower than the MRL, it is deemed safe for human consumption. An MRL of $10 \mu \mathrm{g} /$ $\mathrm{kg}$ has been established in the European Union for the sum of TCB residues expressed as keto-triclabendazole (keto-TCB) residues following correction for recovery. Alternatively, residues can be extracted from samples, hydrolyzed under alkaline conditions, and oxidized to keto-TCB (European Medicines Agency, 1997). In practice, most laboratories test for TCB, triclabendazole sulfoxide, triclabendazole sulfone, and keto-TCB. Results can then be expressed as keto-TCB using the protocol outlined by Cooper et al. (2011). Setting of an MRL and withdrawal period is a necessary step for all licensed medicinal drugs administered to livestock that produce food for human consumption, and these withdrawal periods must be strictly observed (Defra, 2008). The withdrawal period can vary depending on factors such as animal species, dose, product formulation, administration method, and food being produced (Moreno et al., 2005). Provisional MRL were set for the flukicides clorsulon (European Commission, 2012a), closantel (European Commission, 2012b), nitroxynil (European Commission, 2012c), and TCB (European Commission, 2012d), following a scientific review by the European Medicinal Agency's Committee on Veterinary Medicinal Products (CVMP). These are due to expire January 1, 2014.

Few studies have been undertaken on the migration of TCB residues from milk to dairy products and their stability therein. To determine such migration is important for risk assessment and exposure assessment and to determine the potential concentration of residues in milk products following different manufacturing processes. Some studies have been reported on residues in milk and dairy products subsequent to treatment of lactating cows with other flukicide products such as closantel and oxyclozanide in milk powder (Michiels et al., 1987; Whelan et al., 2010; Power et al., 2012), ivermectin in cheese (Imperiale et al., 2004), and sulfamethazine in powder (Malik et al., 1994). However, these studies have looked at the migration of residues in a limited range of dairy products.

The objective of this study was to determine the migration pattern of TCB residues from the milk of treated animals to a range of dairy products, including cheese, skim milk powder, and butter, and to assess the stability of such residues during processing and during storage.

\section{MATERIALS AND METHODS}

\section{Chemicals and Reagents}

Acetonitrile, methanol, ammonium formate (all liquid chromatography-mass spectrometry grade), $\mathrm{NaCl}$, and anhydrous $\mathrm{MgSO}_{4}$ (both analytical grade) were sourced from Sigma-Aldrich (Dublin, Ireland) and VWR (Leicester, UK). Acetonitrile (pesticide grade), formic acid, trifluoracetic acid, and dimethyl sulfoxide (all analytical grade) were sourced from BDH Chemicals Ltd. (Poole, UK). Dispersive solid-phase extraction tubes containing $\mathrm{C}_{18}(0.5 \mathrm{~g})$ and $\mathrm{MgSO}_{4}(1.5 \mathrm{~g})$ were supplied by Agilent Technologies (Santa Clara, CA). Ultra-pure water $(18.2 \mathrm{M} \Omega)$ was generated in-house using a Millipore water purification system (Millipore, Billerica, MA). Triclabendazole, triclabendazole sulfoxide (TCB-SO), triclabendazole sulfone $\left(\mathbf{T C B}-\mathbf{S O}_{2}\right)$, keto-TCB, triclabendazole-amine ( $\left.\mathbf{T C B}-\mathbf{N H}_{2}\right)$ and TCB-D3 were purchased from Witega Laboratories (Berlin, Germany). Primary stock solutions were prepared for analytical standards (TCB, TCB-SO, TCB$\mathrm{SO}_{2}$, and keto-TCB) at a concentration of $2 \mathrm{mg} / \mathrm{mL}$ in methanol (MeOH). Mixed working standard solutions were prepared by diluting primary stock solutions in $\mathrm{MeOH}$, and TCB-D3 and TCB- $\mathrm{NH}_{2}$ (internal stan- 


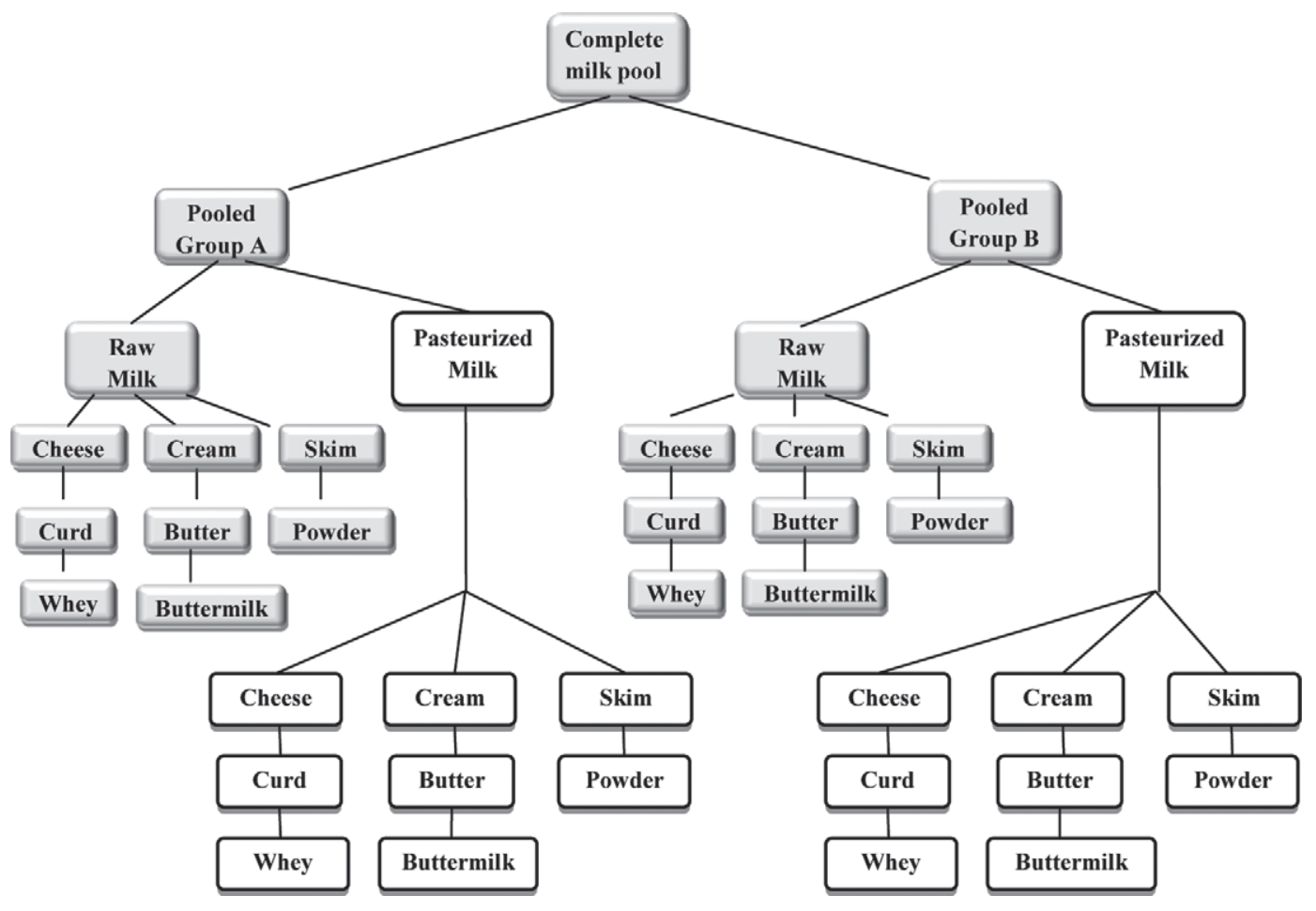

Figure 1. Flowchart of the process of product manufacture from milk containing high and low levels of triclabendazole residues.

dards) were prepared at a concentration of $1 \mathrm{mg} / \mathrm{mL}$ in $\mathrm{MeOD}$ (deuterated $\mathrm{MeOH}$ ) and $\mathrm{MeOH}$, respectively. Intermediate and working internal standards were prepared at 100 and $4 \mu \mathrm{g} / \mathrm{mL}$ in $\mathrm{MeOD}$, respectively.

\section{Design of Dairy Processing Experiments}

A total of 6 lactating dairy cows (Friesian, $\mathrm{n}=3$; Montbéliarde, $\mathrm{n}=2$; Norwegian Red, $\mathrm{n}=1$ ) were assigned to the experiment. A $50-\mathrm{mL}$ pretreatment milk sample was collected from each cow. Cows were then weighed and Fasinex 10\% administered orally at a rate of $12 \mathrm{~mL} / 100 \mathrm{~kg}$ of live weight according to the manufacturer's instructions. Cows were divided into 2 groups of 3 cows (balanced by breed as much as possible). The milk used for the manufacture of dairy products containing high TCB residue concentrations was taken on $\mathrm{d} 2$ after treatment and contained $1,520 \pm 97 \mu \mathrm{g} / \mathrm{kg}$ $(\mathrm{n}=3$, group 1) and $1,538 \pm 349 \mu \mathrm{g} / \mathrm{kg}(\mathrm{n}=3$, group 2 ), whereas that containing low TCB residue concentrations was taken at d 23 and contained $0 \mu \mathrm{g} / \mathrm{kg}(\mathrm{n}=$ 3 , group 1$)$ and $0 \mu \mathrm{g} / \mathrm{kg}(\mathrm{n}=3$, group 2$)$.

Each milk pool, from group 1 and group 2 cows, was sampled and analyzed for TCB residues. Each milk group was then subdivided and one part was pasteurized $\left(72^{\circ} \mathrm{C} \times 15 \mathrm{~s}\right)$ and the second part remained unpasteurized (raw). Semi-soft laboratory-scale cheese was manufactured using milk from each pasteurized and unpasteurized milk group, at high and low residue concentrations, as described later. During the cheesemaking process, the curd and whey were sampled after separation and analyzed for TCB residues, in addition to the final cheese. Separate portions of the same milks used in cheese manufacture were separated into skim milk and cream fractions. These fractions were used for the manufacture of butter, buttermilk, and skim milk powder. Figure 1 shows a flowchart for the experimental process.

\section{Cheesemaking}

Milk (10 L; pasteurized and unpasteurized), at an initial $\mathrm{pH}$ value of 6.7 , was transferred into separate vats and heated to $32^{\circ} \mathrm{C}$ with constant gentle agitation while regularly monitoring the $\mathrm{pH}$. When the temperature reached $20^{\circ} \mathrm{C}, 1 \mathrm{~g}$ of starter culture (direct vat set, EU RST 631; Chr. Hansen, Little Island, Cork, Ireland) was added. The milk was ripened until the $\mathrm{pH}$ decreased below $\mathrm{pH} 6.55$ (20-45 min) when rennet was added $(1.7 \mathrm{~mL}$ diluted in $200 \mathrm{~mL}$ of sterile water). The curd was allowed to set for 75 min until it was firm enough to cut. The curd was cut into cubes (approximately $1 \mathrm{~cm}^{3}$ ), stirred for $5 \mathrm{~min}$ and the temperature was increased to a final temperature of $36^{\circ} \mathrm{C}$ at a rate of $1^{\circ} \mathrm{C}$ every $5 \mathrm{~min}$, while stirring continuously. After cooking, the curd was placed into cheese molds 
when the $\mathrm{pH}$ was at or below $\mathrm{pH}$ 6.4. The cheeses were turned every $30 \mathrm{~min}$ for $3 \mathrm{~h}$ and every $90 \mathrm{~min}$ thereafter until brining. The molds were maintained at ambient temperature until the $\mathrm{pH}$ decreased to $\mathrm{pH} 5.25$ to 5.3 (8-10 h postmolding). Cheese was brined by immersing it in a $23 \%$ brine solution for 75 min. The cheese was then drained for 10 min postbrining and sampled. The cheese was subsequently ripened at $14^{\circ} \mathrm{C}$ and sampled weekly for 4 wk during ripening and analyzed each week for TCB residues.

\section{Separation of Whole Milk to Skim Milk and Cream}

Milk was heated to $50^{\circ} \mathrm{C}$ and separated using a Disc Bowl Centrifuge (Armfield, Hampshire, UK). Cream and skim milk fractions were collected.

\section{Manufacture of Butter}

Following the separation of milk into skim milk and cream, the cream was chilled and whisked in a food blender until the cream separated into buttermilk and butter. Buttermilk, skim milk, and cream samples were analyzed on day of manufacture (d 0).

Butter was stored in refrigerated storage at $4^{\circ} \mathrm{C}$ for $4 \mathrm{wk}$, and sample aliquots were taken each week and analyzed for stability of the residue over time in the refrigerated product.

\section{Manufacture of Skim Milk Powder}

A laboratory-scale Buchi Mini Spray Dryer B-191 (Buchi, Flawil, Switzerland) was used for manufacture of skim milk powder. Before spray drying, the skim milk was heated to $50^{\circ} \mathrm{C}$. The skim milk suspension was pneumatically atomized into a vertical drying chamber using a 2-fluid nozzle system. The inlet temperature was maintained at $185^{\circ} \mathrm{C} \pm 2^{\circ} \mathrm{C}$ throughout the drying process. The flow rate of the skim milk suspension was varied by the adjustment of controls wherein this flow rate controlled the outlet air-temperature, which was maintained at $90^{\circ} \mathrm{C} \pm 2^{\circ} \mathrm{C}$. Spray-dried samples were collected at the base of the cyclone.

To prevent cross-contamination of residue between skim milk powder from different drying runs, the spray drier was dismantled and cleaned between each spraydrying run. Following reassembly, distilled water was pumped through for a minimum of $1 \mathrm{~h}$.

\section{Sample Preparation}

Milk, whey, powder, and buttermilk samples were manually mixed end-over-end to ensure sample homogeneity before taking a sample aliquot. A $10 \mathrm{~g}( \pm 0.1$ g) quantity of milk, buttermilk, skim milk, or whey sample was weighed into a 50-mL centrifuge tube. Butter, cheese, cream, curd, or powder samples ( $1 \mathrm{~g} \pm 0.01$ g) were weighed into centrifuge tubes $(50 \mathrm{~mL})$ and ultrapure water $(9 \mathrm{~mL})$ was added. The tubes containing cheese, curd, and butter were placed in a water bath at $50^{\circ} \mathrm{C}$ until the product and water became homogeneous. Samples, extracted matrix calibrants, and recovery controls were fortified with $25 \mu \mathrm{L}$ of internal standard.

Extracted matrix calibrants were also fortified with $100 \mu \mathrm{L}$ of working standard solutions 1 to 8 (described later in Calibration and Controls section), and all fortified samples were left to sit for $15 \mathrm{~min}$. Pesticide-grade acetonitrile $(12 \mathrm{~mL})$ was added to each tube; $\mathrm{MgSO}_{4}$ $(4 \mathrm{~g})$ and $\mathrm{NaCl}(1 \mathrm{~g})$ were subsequently added to each tube in batches of 6 and shaken vigorously by hand ( $1 \mathrm{~min}$ ). Tubes were centrifuged at $2,842 \times g$ for 12 min at $4^{\circ} \mathrm{C}$. The upper acetonitrile layer was decanted into 50-mL polypropylene tubes containing $\mathrm{C}_{18}(0.5$ g) and $\mathrm{MgSO}_{4}(1.5 \mathrm{~g})$, which were vortexed $(1 \mathrm{~min})$ and centrifuged at $1,449 \times g$ for $10 \mathrm{~min}$ at $4^{\circ} \mathrm{C}$. A 6 -mL portion of the supernatant was transferred into a $15-\mathrm{mL}$ polypropylene tube containing $0.25 \mathrm{~mL}$ of dimethyl sulfoxide. The tubes were placed in a Turbovap evaporator Caliper Life Sciences (Runcorn, UK) and the acetonitrile was evaporated at $50^{\circ} \mathrm{C}$. Extracts were filtered through $0.2-\mu \mathrm{m}$ polytetrafluroethylene syringe filters (Whatman Rezist, Fisher Scientific, Dublin, Ireland), transferred to HPLC vials and analyzed by ultrahigh performance liquid chromatography tandem mass-spectrometry (UHPLC-MS/MS).

\section{UHPLC-MS/MS Analysis}

Sample analysis was carried out using the UHPLCMS/MS system described elsewhere (Power et al., 2013). In brief, separations were performed using a Waters (Milford, MA) Acquity UPLC system comprising a stainless steel HSS T3 analytical column $(100 \mathrm{~mm} \times$ $2.1 \mathrm{~mm}$, particle size $1.8 \mu \mathrm{m}$ ) equipped with an in-line filter unit containing a $0.2-\mu \mathrm{m}$ stainless steel replacement filter maintained at a temperature of $60^{\circ} \mathrm{C}$, and the pump was operated at a flow rate of $0.6 \mathrm{~mL} / \mathrm{min}$. A binary gradient system was used to separate analytes comprising mobile phase A, $0.1 \%$ trifluoroacetic acid in water:MeOH (80:20, vol/vol) and mobile phase B, $0.1 \%$ trifluoroacetic acid in $\mathrm{MeOH}$ ( $\mathrm{vol} / \mathrm{vol}$ ). The gradient profile was as follows: (1) $0 \mathrm{~min}, 100 \% \mathrm{~A}$, (2) 2 to 2.5 min, $0 \%$ A, (3) 2.51 to $5.5 \mathrm{~min}, 100 \% \mathrm{~A}$. The injection volume was $4 \mu \mathrm{L}$. This resulted in an extended calibration range from 5 to $1,000 \mu \mathrm{g} / \mathrm{kg}$. Purified extracts were analyzed for TCB, TCB-SO, TCB-SO $\mathrm{S}_{2}$, and keto-TCB residues. Analytes were detected using a Quattro Premier XE triple quadrupole mass spectrometer (Waters, 
Milford, MA), equipped with an electrospray ionization source operating in positive mode; MS conditions are outlined by Power et al. (2013).

\section{Calibration and Controls}

Calibration curves were prepared by fortifying negative samples before extraction with TCB working standard solutions prepared at the following concentrations (in $\mu \mathrm{g} / \mathrm{mL}$ ): 10 (standard 8), 5 (standard 7), 2.5 (standard 6), 1 (standard 5), 0.5 (standard 4), 0.25 (standard 3), 0.1 (standard 2), and 0.05 (standard 1). Extracted matrix calibration curves were prepared by fortifying negative samples before extraction with 100 $\mu \mathrm{L}$ of the standards to give working standard curves in the range of 5 to $1,000 \mu \mathrm{g} / \mathrm{kg}$ (milk, buttermilk, skim milk and whey) and 50 to $10,000 \mu \mathrm{g} / \mathrm{kg}$ (butter, cheese, cream, curd, and powder). An additional 4 blank matrix samples (recovery controls) were spiked after evaporation to monitor for loss of analytes during extraction, 2 with $50 \mu \mathrm{L}$ of standard 2 , and 2 with 50 $\mu \mathrm{L}$ of standard 7 . This gave concentrations of 10 and $500 \mu \mathrm{g} / \mathrm{kg}$ for milk, buttermilk, skim milk, and whey, or 100 and $5,000 \mu \mathrm{g} / \mathrm{kg}$ for butter, cheese, cream, curd, and powder, respectively.

\section{Method Validation}

The following analytical method performance parameters were investigated: within-laboratory reproducibility, within-laboratory repeatability, specificity, linearity, and accuracy. The validation of the method for the determination of TCB residues in milk has been described elsewhere (Power et al., 2013).

The method was validated for use in dairy products according to European Legislation outlined in Regulation 2002/657/EC (European Commission, 2002). Validation of the method was conducted in skim milk powder, butter, and soft cheese, all manufactured from bovine milk. The dairy product validations were carried out by fortifying negative controls (butter, soft cheese, and skim milk powder) at 50,100, and $150 \mu \mathrm{g} /$ $\mathrm{kg}$. A range of dairy product samples were analyzed by UHPLC-MS/MS before validation to evaluate the selectivity of the method and identify a suitable negative control that did not contain TCB residues. In each case, the samples were analyzed using a curve prepared in the corresponding dairy product matrix.

\section{Stability of TCB Residues in Dairy Products}

Butter samples, stored for up to 4 wk at $4^{\circ} \mathrm{C}$, were analyzed weekly for TCB residues in fresh product. Once each weekly sample had been taken, the remain- ing butter aliquot from which the sample was taken was frozen at $-20^{\circ} \mathrm{C}$ for further residue stability analysis at mo 6 and 12. Cheese, stored for up to $4 \mathrm{wk}$ at $14^{\circ} \mathrm{C}$, was sampled and analyzed weekly for TCB residue analysis in fresh product. Once each weekly sample had been taken, the remaining cheese aliquot from which the sample was taken was frozen at $-20^{\circ} \mathrm{C}$ for further residue stability analysis at mo 6 and 12. Buttermilk, skim milk, cream, curd, and whey samples were analyzed from fresh product on d 0 , frozen immediately at $-20^{\circ} \mathrm{C}$, and stored at that temperature for further residue stability analysis at mo 6 and 12. Skim milk powder was stored in $50-\mathrm{mL}$ centrifuge tubes in the dark at ambient temperature $\left(18-22^{\circ} \mathrm{C}\right)$. Samples of powder were taken and analyzed for TCB residues on $\mathrm{d}$ 0 , and at 6 and 12 mo.

\section{Statistical Analyses}

All statistical analyses were carried out using SAS (JMP version 10, SAS Institute Inc., Cary, NC). A randomized design that incorporated the treatment (pasteurized and unpasteurized) and the effect of residue over time was used. The response variables related to the cheese and butter manufactured using pasteurized and unpasteurized milk. Small sample sizes affected the assumptions of normality. Therefore, nonparametric statistical methods were used for data analysis, and both values for each 3-cow group are shown. Statistically significant differences $(P<0.05)$ between treatments and time were determined by using Kruskal-Wallis nonparametric one-way ANOVA and the Mann-Whitney-Wilcoxon test.

\section{RESULTS}

\section{Validation of TCB Residue Measurements in Product}

According to European validation criteria (European Commission, 2002), analytical methods must be validated at $0.5,1.0$, and 1.5 times the MRL. No MRL have been set for TCB residues in dairy products, so arbitrary levels of 50,100, and $150 \mu \mathrm{g} / \mathrm{kg}$ for butter, cheese, and powder were used. In addition, accuracy should be in the range of 80 to $110 \%$ for samples fortified at concentrations $\geq 10 \mu \mathrm{g} / \mathrm{kg}$ and precision should be $\leq 20 \%$ and $\leq 16 \%$ at concentrations of $\leq 100 \mu \mathrm{g} / \mathrm{kg}$ and $1,000 \mu \mathrm{g} / \mathrm{kg}$, respectively. Validation results were largely acceptable for TCB, TCB-SO, and TCB-SO ${ }_{2}$ residues in different dairy products (Table 1). Mean accuracy ranged from 91 to $110 \%$ and precision from 3 to $17 \%$. Precision results were satisfactory for ketoTCB in skim milk powder but accuracy was marginally outside the acceptable limits in butter (113 and 119\%). 
Table 1. Triclabendazole residue validations (tested at 50,100, and $150 \mu \mathrm{g} / \mathrm{kg}$ ) for all 4 analytes in skim milk powder, butter, and cheese

\begin{tabular}{|c|c|c|c|c|c|c|c|c|c|c|c|c|}
\hline \multirow[b]{2}{*}{ Product } & \multicolumn{3}{|c|}{$\begin{array}{l}\text { Triclabendazole } \\
(\mu \mathrm{g} / \mathrm{kg})\end{array}$} & \multicolumn{3}{|c|}{$\begin{array}{c}\text { Triclabendazole-sulfoxide } \\
(\mu \mathrm{g} / \mathrm{kg})\end{array}$} & \multicolumn{3}{|c|}{$\begin{array}{c}\text { Triclabendazole-sulfone } \\
(\mu \mathrm{g} / \mathrm{kg})\end{array}$} & \multicolumn{3}{|c|}{$\begin{array}{l}\text { Keto-triclabendazole } \\
(\mu \mathrm{g} / \mathrm{kg})\end{array}$} \\
\hline & 50 & 100 & 150 & 50 & 100 & 150 & 50 & 100 & 150 & 50 & 100 & 150 \\
\hline Mean $(\mu \mathrm{g} / \mathrm{kg})$ & 45 & 102 & 158 & 47 & 102 & 152 & 49 & 110 & 160 & 42 & 98 & 138 \\
\hline $\mathrm{SD}(\mu \mathrm{g} / \mathrm{kg})$ & 3.3 & 6.8 & 9.7 & 3.7 & 10.4 & 7.8 & 4.6 & 10.2 & 6.4 & 3.5 & 14.3 & 13.3 \\
\hline $\mathrm{CV}(\%)$ & 7.3 & 6.7 & 6.2 & 7.8 & 10.1 & 5.1 & 9.5 & 9.2 & 4.0 & 8.4 & 14.6 & 9.6 \\
\hline $\mathrm{SD}(\mu \mathrm{g} / \mathrm{kg})$ & 7.1 & 8.4 & 11.8 & 4.2 & 3.2 & 12.4 & 7.6 & 5.2 & 6.9 & 8.0 & 20.0 & 20.2 \\
\hline $\mathrm{CV}(\%)$ & 13.0 & 8.0 & 8.1 & 8.3 & 3.1 & 8.6 & 15.9 & 5.4 & 4.7 & 13.4 & 17.7 & 12.9 \\
\hline Accuracy (\%) & 109 & 105 & 97 & 101 & 101 & 96 & 95 & 95 & 98 & 119 & 113 & 105 \\
\hline \multicolumn{13}{|l|}{ Cheese } \\
\hline Mean $(\mu \mathrm{g} / \mathrm{kg})$ & 55 & 110 & 162 & 52 & 109 & 158 & 49 & 98 & 142 & 41 & 119 & 174 \\
\hline $\mathrm{SD}(\mu \mathrm{g} / \mathrm{kg})$ & 4.2 & 5.5 & 4.7 & 9.0 & 11.5 & 11.4 & 3.7 & 6.8 & 14.4 & 10.4 & 43.3 & 31.7 \\
\hline
\end{tabular}

Similarly, precision was marginally outside the acceptable range for keto-TCB in cheese, with results in the range in 82 to $119 \%$. Precision was less satisfactory for keto-TCB, with values in the range of 18 to $36 \%$.

\section{Transfer of TCB Residues into Cream, Skim Milk, and Subsequent Products}

When milk containing high residue concentrations was separated, TCB residues concentrated in the cream, with $<10 \%$ of the residues remaining in the skim-milk. Triclabendazole, TCB-SO, TCB-SO ${ }_{2}$, and keto-TCB were expressed as keto-TCB and summed ( $\Sigma$ keto-TCB). These values were calculated according to the method described by Cooper et al. (2011). The potential exists that other residues in milk could occur that can be extracted and transformed to keto-TCB following derivatization. In a recently reported study with radiolabeled TCB (oral dose of $11.57 \mathrm{mg} / \mathrm{kg}$ of $\mathrm{BW}$ ), the total TCB radioactive residue concentration in milk was $2,102 \mu \mathrm{g} / \mathrm{kg}$ on $\mathrm{d} 2$ (European Medicines Agency, 2012). Keto-TCB constituted 61 to $82 \%$ (1,282 or $1,724 \mu \mathrm{g} / \mathrm{kg}$ ) of the total radioactive residues. More recently, Power et al. (2013) showed that the mean concentration of summed TCB residues expressed as keto-TCB was $1,703 \mu \mathrm{g} / \mathrm{kg}$ on $\mathrm{d} 2$. This suggests that TCB, TCB-SO, TCB-SO ${ }_{2}$, and keto-TCB are the major metabolites that occur in milk. The close correlation between these studies indicates that if other residues occur, it is likely that they occur at low concentrations. In milk targeted to contain low residue concentrations (i.e., milk collected on d 23), no TCB was detected. However, after separation, TCB residues were detected in the cream, but not in the skim milk. Pasteurized and unpasteurized skim milk did not differ significantly $(P$ $>0.05$; Table 2).
When high residue concentration cream was converted to butter, approximately $85 \%$ of the residues migrated with the fat, resulting in butter with a high concentration of residues; the remaining $15 \%$ of the residues migrated to the buttermilk. Similarly, in cream with a low residue concentration, the majority of the residues migrated with the fat to the butter, with relatively little in the buttermilk (Table 2). Again, pasteurized and unpasteurized skim milk did not differ $(P>$ $0.05)$. When skim milk powder was manufactured from skim milk containing a high concentration of residues, the residue concentration in the skim milk powder increased by a factor of 15 compared with the starting skim milk. When no residues were detected in the skim milk, none were detected in the skim milk powder (Table 2). For skim milk powder, $\Sigma$ keto-TCB residues detected in skim milk powder made from pasteurized and unpasteurized milk did not differ $(P>0.05)$.

\section{Transfer of TCB Residues into Cheese}

In milk targeted to contain high concentrations of residues, $\Sigma$ keto-TCB residues ranged from 600 to 1,500 $\mu \mathrm{g} / \mathrm{kg}$. Again, no residues were detectable in milk targeted to contain low TCB concentrations. In cheese manufactured from milk with high residue concentrations, $\Sigma$ keto-TCB residues were approximately 4 times higher in curd compared with the starting milk, with only about $5 \%$ lost in the whey (Table 3 ). The migration of residue to cheese or loss of residue in the whey made from pasteurized milk was not significantly different from that manufactured with unpasteurized milk with either high or low residue concentrations $(P>0.05)$.

In all cases, the curd samples were taken immediately after cutting the curd. Due to continued expulsion of whey from the curd during the remainder of the chee- 
Table 2. The sum of keto-triclabendazole (TCB) residues $(\mu \mathrm{g} / \mathrm{kg})$ in milk, skim milk, cream, skim milk powder, butter, and buttermilk made from pasteurized and unpasteurized milk containing high and low concentrations of residues $^{1}$

\begin{tabular}{lccccc}
\hline & \multicolumn{2}{c}{ High residue } & & \multicolumn{2}{c}{ Low residue } \\
\cline { 2 - 3 } \cline { 5 - 6 } Product & Unpasteurized & Pasteurized & & Unpasteurized & Pasteurized \\
\hline Milk & 1,$082 ; 1,001$ & 1,$505 ; 841$ & & $<5^{2} ;<5$ & $<5 ;<5$ \\
Skim milk & $423 ; 508$ & $420 ; 414$ & & $<5 ;<5$ & $<5 ;<5$ \\
Cream & 7,$589 ; 10,757$ & 6,$981 ; 8,350$ & & $<50 ;<50$ & $<50 ;<50$ \\
Skim milk powder & 7,$252 ; 5,119$ & 7,$242 ; 4,170$ & & $<50 ;<50$ & $<50 ;<50$ \\
Butter & 9,$177 ; 8,027$ & 9,$657 ; 12,201$ & & $<50 ;<50$ & $<50 ;<50$ \\
Buttermilk & 1,$644 ; 1,900$ & $\mathrm{ND}^{3} ; 1,570$ & & $<5 ;<5$ & $<5 ;<5$ \\
\hline
\end{tabular}

${ }^{1}$ Independent duplicate experiments were undertaken and both values are shown.

${ }^{2} \mathrm{TCB}$ and its metabolites were detectable in samples but at levels below the limit of quantification.

${ }^{3}$ Not determined.

semaking process, the concentration of residues in the cheese was higher than that in the curd, except for cheese made from pasteurized milk with high residues, in which similar residue concentrations were detected in curd and cheese. With continued reductions in the moisture of the cheese during ripening (data not shown), the residue concentration in the cheese increased significantly $(P<0.05)$ between cheese ripened for $2 \mathrm{wk}$ and that ripened for $4 \mathrm{wk}$ (Table 3 ).

Although no residues were detected in milk targeted to contain low residue concentrations, residues were detectable at below the limit of quantification in 1 curd sample. No residues were detected in the other curd samples, but as the whey continued to be expressed during the remainder of the cheese-making process, increasing concentrations of residue were detected during cheese ripening. Similar results were obtained for pasteurized and unpasteurized milk cheeses (Table 3).

\section{Stability of TCB Residues in Dairy Products}

Stability of TCB residues was measured in butter, cheese, and skim milk powder over time in fresh product and during frozen storage $\left(\right.$ at $\left.-20^{\circ} \mathrm{C}\right)$ of milk, but- ter, curd, whey, and buttermilk samples for 6 , and in some cases 12, mo. Butter was stored at $4^{\circ} \mathrm{C}$ for $3 \mathrm{wk}$ and analyzed weekly.

During storage of butter (unfrozen) manufactured from pasteurized or unpasteurized milk, we found no significant difference $(P>0.05)$ in the concentrations of $\Sigma$ keto-TCB residues detected (Table 4). Except for 1 outlier at wk 3 for butter made from pasteurized milk, we found no significant difference $(P>0.05)$ in the concentrations of $\Sigma$ keto-TCB residues detected during storage (unfrozen) of butter made from milk containing a low concentration of residues (Table 4). During frozen storage of the pasteurized and unpasteurized butter samples, the concentration of $\Sigma$ keto-TCB residues detected in samples analyzed at d 0 and those analyzed after freezing for 6 or 12 mo did not differ $(P>0.05)$.

Skim milk powder samples were stored at ambient temperature $\left(18-22^{\circ} \mathrm{C}\right)$ for up to 12 mo and were not frozen. Under these storage conditions, TCB residues were not stable in the skim milk powder manufactured from pasteurized or unpasteurized milk with a high concentration of residues. No TCB residues were detected in the powder made from milk with a low concentration of residues.

Table 3. The sum of keto-triclabendazole (TCB) residues $(\mu \mathrm{g} / \mathrm{kg})$ in curd, whey, and cheese for each of the pasteurized and unpasteurized milks containing high and low concentrations of residues ${ }^{1}$

\begin{tabular}{|c|c|c|c|c|}
\hline \multirow[b]{2}{*}{ Product } & \multicolumn{2}{|c|}{ High residue } & \multicolumn{2}{|c|}{ Low residue } \\
\hline & Unpasteurized & Pasteurized & Unpasteurized & Pasteurized \\
\hline$\overline{\text { Milk }}$ & $918 ; 850$ & $611 ; 752$ & $<5^{2} ;<5$ & $<5 ;<5$ \\
\hline Curd & 4,$532 ; 5,672$ & 5,$699 ; 3,664$ & $<50^{1} ;<50$ & $<50 ;<50$ \\
\hline Whey & $219 ; 180$ & $173 ; 185$ & $<5 ;<5$ & $<5 ;<5$ \\
\hline Cheese wk $0^{3}$ & 5,$372 ; 4,784$ & 5,$560 ; 4,641$ & $<50 ;<50$ & $<50 ;<50$ \\
\hline Cheese wk 1 & 3,$825 ; 4,872$ & 4,$872 ; 3,938$ & $<50 ;<50$ & $<50 ;<50$ \\
\hline Cheese wk 2 & 9,$066 ; 4,646$ & 7,$062 ; 5,680$ & $<50 ;<50$ & $<50 ;<50$ \\
\hline Cheese wk 3 & 7,$611 ; 4,930$ & 9,$008 ; 4,560$ & $<50 ;<50$ & $<50 ;<50$ \\
\hline
\end{tabular}




\section{DISCUSSION}

The results of this study show that in dairy products manufactured from milk containing TCB residues, the residues migrated with the fat, resulting in higher concentrations of $\Sigma$ keto-TCB residues in cream, butter, and cheese than in skim milk, buttermilk, or whey. Concentrations of $\Sigma$ keto-TCB residues following migration from pasteurized and unpasteurized milk did not differ.

Limited studies have been conducted on the migration of flukicide residues from milk to dairy products or on the stability of residues in product. Similar to the current study, Imperiale et al. (2011) showed that TCB residues concentrated in cheese by a factor of 13 compared with the starting milk. The significance of this result is that $\Sigma$ keto-TCB residues concentrate in cheese during the cheese-making process, indicating that cheese made with milk containing undetectable concentrations of residues could result in cheese with detectable residue concentrations.

The migration to whey, the effect of pasteurization of the residue concentrations, and the stability of the residues during cheese were not studied by Imperiale et al. (2011). These issues were addressed in the current study, which showed that less than $5 \%$ of the residue migrated with the whey and that residue concentrations in cheese or whey manufactured from either pasteurized or unpasteurized milk did not differ; thus, heat treating to $72^{\circ} \mathrm{C}$ did not affect the presence of TCB residues.

When milk containing TCB residues was separated, the residues migrated with the cream and subsequently to butter rather than buttermilk. Triclabendazole and its metabolites are therefore fat-soluble residues. Previous studies on fat-soluble ivermectin (IVM) and moxidectin (MXD) in lactating sheep and during cheese production and ripening showed that, similar to the current study, concentrations of IVM and MXD gradually increased in cheese during the ripening period up to $40 \mathrm{~d}$ (Imperiale et al., 2004). The thermal stability of IVM, MXD, and eprinomectin (EPM) in ewe milk at $65^{\circ} \mathrm{C}$ for 30 min and at $75^{\circ} \mathrm{C}$ for $15 \mathrm{~s}$ has also been shown (Imperiale et al., 2009). In addition, Cerkvenik et al. (2004) showed that IVM, MXD, and EPM residues were stable during heat treatment at temperatures of up to $90^{\circ} \mathrm{C}$ in ewe milk, cheese, and yogurt. Similarly, the stability of $\Sigma$ keto-TCB residues has been demonstrated during roasting and frying of TCBcontaminated beef at internal temperatures of $92.9^{\circ} \mathrm{C}$ and $67.3^{\circ} \mathrm{C}$, respectively (Cooper et al., 2011). Similar heat stability of other veterinary drugs (clenbuterol, levamisole, sulfamethazine, and oxytetracycline) was investigated during different cooking processes (Rose et al., 1995a,b,c, 1996). Clenbuterol, levamisole, and sulfa-

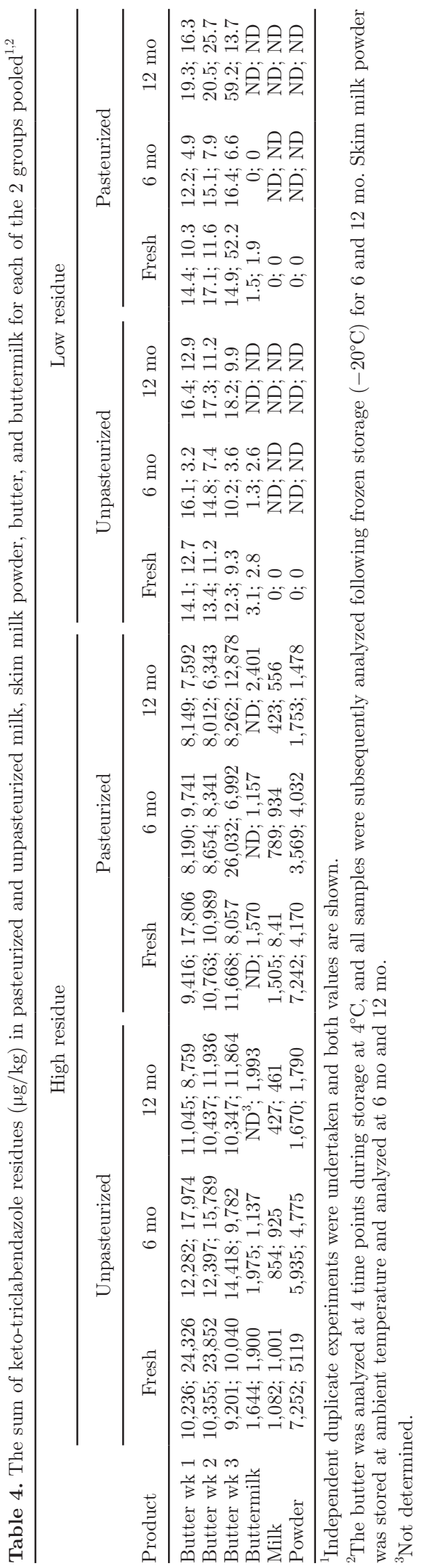


methazine were stable during these cooking processes, with the exception of deep frying; all 3 analytes were unstable following that cooking process, and oxytetracycline was unstable during all cooking processes.

In this study, TCB and its metabolites migrated with the fat. This is in contrast to the migration of the flukicides nitroxynil, oxyclosanide, and levamisole, where $>90 \%$ of the residue migrated with the skim milk and were transferred to the skim milk powder (Power et al., 2012). The significance of this result is that the concentration of $\Sigma$ keto-TCB residues did not decrease during powder manufacture, despite the high temperature required for the process.

Less than $10 \%$ of the $\Sigma$ keto-TCB residues migrated to the skim milk. When skim milk powder was manufactured from this skim milk, the residues concentrated in the skim milk powder. The temperatures used in powder manufacturing had no effect on the concentration of the residues. The concentration factor of the residues in the powder was approximately 15 .

No previous study has been undertaken on the stability of TCB and its metabolites in dairy products under freezing conditions. However, Cerkvenik et al. (2001) studied the stability of IVM residues in unpasteurized and pasteurized sheep milk during storage at $-20^{\circ} \mathrm{C}$ for a period of more than $2 \mathrm{yr}$. In that study, milk from 13 ewes administered IVM at $0.2 \mathrm{mg} / \mathrm{kg}$ of BW during lactation was collected each day for up to $9 \mathrm{~d}$ following administration. A portion of each milk sample was frozen with no heat treatment, whereas the remainder of each sample collected was subjected to 3 separate heat treatments: $74^{\circ} \mathrm{C}$ for $40 \mathrm{~s}, 80^{\circ} \mathrm{C}$ for $1 \mathrm{~min}$, and $100^{\circ} \mathrm{C}$ for $10 \mathrm{~s}$. The results demonstrated no significant difference in the IVM concentrations among the 3 heat-treated milks and the unpasteurized milk. In addition, no reduction of IVM residues was found during the first year of storage at $-20^{\circ} \mathrm{C}$; however, following $2 \mathrm{yr}$ of freezer storage, the concentrations IVM residues decreased significantly.

\section{CONCLUSIONS}

Experimental results from dairy product manufacture demonstrated that TCB and its metabolites migrated with the milk fat and concentrated in cheese, curd, butter, and cream products, with less than $5 \%$ found in the whey and skim milk. The results indicate that keto-TCB residues do not degrade during the heating temperatures used during pasteurization or powder and cheese manufacturing processes. Some products made with milk having undetectable levels of residues did show detectable concentrations of residues in the subsequent product; therefore, a wider food safety issue may exist.

\section{ACKNOWLEDGMENTS}

This work was supported by the Dairy Levy Trust. The authors acknowledge the staff at Teagasc Food Research Centre, Ashtown, in particular Martin McCormack, and the farm staff at Teagasc Food Research Centre, Moorepark, in particular Noel Byrne and John Paul Murphy, for their valuable assistance. Clare Power was in receipt of a Teagasc Walsh Fellowship.

\section{REFERENCES}

Alvarez, L., G. Moreno, L. Moreno, L. Ceballos, L. Shaw, I. Fairweather, and C. Lanusse. 2009. Comparative assessment of albendazole and triclabendazole ovicidal activity on Fasciola hepatica eggs. Vet. Parasitol. 164:211-216.

Animal Health Ireland. 2011. Liver fluke: The facts. Parasites Leaflet Number 5, Version 1 July 2011. Animal Health Ireland, Carrickon-Shannon, Co. Leitrim, Ireland.

Brennan, G. P., I. Fairweather, A. Trudgett, E. Hoey, M. McCoy, M. McConville, M. Meaney, M. Robinson, N. McFerran, L. Ryan, C. Lanusse, L. Mottier, L. Alvarez, H. Solana, G. Virkel, and P. M. Brophy. 2007. Understanding triclabendazole resistance. Exp. Mol. Pathol. 82:104-109.

Cerkvenik, V., D. Z. Doganoc, V. Skubic, W. M. J. Beek, and H. J. Keukens. 2001. Thermal and long-term freezing stability of ivermectin residues in sheep milk. Eur. Food Res. Technol. 213:72-76.

Cerkvenik, V., B. Perko, I. Rogelj, D. Z. Doganoc, V. Skubic, W. M. J. Beek, and H. J. Keukens. 2004. Fate of ivermectin residues in ewes' milk and derived products. J. Dairy Res. 71:39-45.

Cooper, K. M., M. Whelan, M. Danaher, and D. G. Kennedy. 2011. Stability during cooking anthelmintic veterinary drug residues in beef. Food Addit. Contam. A Chem. Anal. Control Expo. Risk Assess. 28:155-165.

Defra. 2008. Veterinary Medicines Directorate: Information sheet on how to determine withdrawal periods Accessed Sep. 20, 2012. http://www.vmd.defra.gov.uk/pdf/leaflet_withdrawalperiod.pdf. Defra, London, UK.

European Commission. 2002. Commission implementing regulation $96 / 23 /$ EC concerning the performance of analytical methods and the interpretation of results 2002/657/EC. Off. J. Eur. Commun. L221:8-36.

European Commission. 2009. Regulation EC. No. 470/2009 of the European Parliament and of the Council of 6 May 2009 laying down Community procedures for the establishment of residue limits of pharmacologically active substances in foodstuffs of animal origin, repealing Council Regulation EC. No. 2377/90 and amending Directive 2001/82/EC of the European Parliament and of the Council and Regulation EC. No. 726/2004 of the European Parliament and of the Council. Off. J. Eur. Commun. L152:11-22.

European Commission. 2010. Commission implementing regulation EU. No. 37/2010 of 22 December 2009 on pharmacologically active substances and their classification regarding maximum residue limits in foodstuffs of animal origin. European Commission, Brussels, Belgium.

European Commission. 2012a. Commission implementing regulation EU. No. 466/2012 of 1 June 2012 amending the Annex to Regulation EU. No. 37/2010 on pharmacologically active substances and their classification regarding maximum residue limits in foodstuffs of animal origin, as regards the substance clorsulon. Off. J. Eur. Commun. L143:2-4.

European Commission. 2012b. Commission implementing regulation EU. No. 221/2012 of 14 March 2012 amending the Annex to Regulation EU. No. 37/2010 on pharmacologically active substances and their classification regarding maximum residue limits in foodstuffs of animal origin, as regards the substance closantel. Off. J. Eur. Commun. L75:7-9.

European Commission. 2012c. Commission implementing regulation EU. No. 201/2012 of 8 March 2012 Amending the Annex to Regu- 
lation EU. No. 37/2010 on pharmacologically active substances and their classification regarding maximum residue limits in foodstuffs of animal origin, as regards the substance nitroxynil. Off. J. Eur. Commun. L71:37-39.

European Commission. 2012d. Commission implementing regulation EU. No. 222/2012 of 14 March 2012 amending the Annex to Regulation EU. No. 37/2010 on pharmacologically active substances and their classification regarding maximum residue limits in foodstuffs of animal origin, as regards the substance triclabendazole. Off. J. Eur. Commun. L75:10-11.

European Medicines Agency. 1997. EMEA/MRL/196/97-FINAL: November 1997. Accessed June 26, 2013. http://www.ema.europa.eu/ ema/index.jsp?curl=pages/includes/document/document_detail. jsp? webContentId=WC500015670\&mid =WC0b01ac058006488e.

European Medicines Agency. 2012. European public MRL assessment report (EPMAR) Triclabendazole (extrapolation to bovine and ovine milk) EMA/CVMP/8136/2011. European Medicines Agency, London, UK.

Flanagan, A. M., H. W. J. Edgar, A. Gordon, R. E. B. Hanna, G. P. Brennan, and I. Fairweather. 2011. Comparison of two assays, a faecal egg count reduction test (FECRT) and a coproantigen reduction test (CRT), for the diagnosis of resistance to triclabendazole in Fasciola hepatica in sheep. Vet. Parasitol. 176:34-42.

Gulay, M. 2004. Altering the lactation cycle: Is a 60-day dry period too long? Turk. J. Vet. Anim. Sci. 25:197-205.

Imperiale, F., M. R. Busetti, V. H. Suarez, and C. E. Lanusse. 2004. Milk excretion of ivermectin and moxidectin in dairy sheep: Assessment of drug residues during cheese elaboration and ripening period. J. Agric. Food Chem. 52:6205-6211.

Imperiale, F., C. Farias, A. Pis, J. M. Sallovitz, A. Lifschitz, and C. Lanusse. 2009. Thermal stability of antiparasitic macrocyclic lactones milk residues during industrial processing. Food Addit. Contam. A Chem. Anal. Control Expo. Risk Assess. 26:57-62.

Imperiale, F., P. Ortiz, M. Cabrera, C. Farias, J. M. Sallovitz, S. Iezzi, J. Perez, L. Alvarez, and C. Lanusse. 2011. Residual concentrations of the flukicidal compound triclabendazole in dairy cows milk and cheese. Food Addit. Contam. A Chem. Anal. Control Expo. Risk Assess. 28:438-445.

Irish Medicine Board. 2012. Fasinex 240: Summary of product characteristics. Accessed Jan. 18, 2013. http://www.imb.ie/images/uploaded/swedocuments/LicenseSPC_10825-004-002_10092012145937. pdf.

Knubben-Schweizer, G., S. Rüegg, P. R. Torgerson, C. Rapsch, F. Grimm, M. Hässig, P. Deplazes, and U. Braun. 2010. Control of bovine fasciolosis in dairy cattle in Switzerland with emphasis on pasture management. Vet. J. 186:188-191.

Malik, S., S. E. Duncan, J. R. Bishop, and L. T. Taylor. 1994. Extraction and detection of sulfamethazine in spray-dried milk. J. Dairy Sci. $77: 418-425$.

McCann, C. M., M. Baylis, and D. J. L. Williams. 2010. Seroprevalence and spatial distribution of Fasciola hepatica-infected dairy herds in England and Wales. Vet. Rec. 166:612-617.
Mezo, M., M. Gonzalez-Warleta, J. A. Castro-Hermida, and F. M. Ubeira. 2008. Evaluation of the flukicide treatment policy for dairy cattle in Galicia (NW Spain). Vet. Parasitol. 157:235-243.

Michiels, M., W. Meuldermanns, and J. Heykants. 1987. The metabolism and fate of closantel (Flukiver) in sheep and cattle. Drug Metab. Rev. 18:235-251.

Moreno, L., F. Imperiale, L. Mottier, L. Alvarez, and C. Lanusse. 2005. Comparison of milk residue profiles after oral and subcutaneous administration of benzimidazole anthelmintics to dairy cows. Anal. Chim. Acta 536:91-99.

O'Brien, B., K. Jordan, and M. Danaher. 2010. Update on the use of flukicides. Ir. Vet. J. 63:702-704.

Olaechea, F., V. Lovera, M. Larroza, F. Raffo, and R. Cabrera. 2011. Resistance of Fasciola hepatica against triclabendazole in cattle in Patagonia (Argentina). Vet. Parasitol. 178:364-366.

Power, C., R. Sayers, B. O'Brien, Y. Bloemhoff, M. Danaher, A. Furey and K. Jordan. 2012. Partitioning of nitroxynil, oxyclosanide and levamisole residues from milk to cream, skim milk and skim milk powder. Int. J. Dairy Technol. 65:503-506.

Power, C., M. Whelan, M. Danaher, Y. Bloemhoff, R. Sayers, B. O'Brien, A. Furey, and K. Jordan. 2013. Investigation of the persistence of triclabendazole residues in bovine milk following lactating-cow and dry-cow treatments. Food Addit. Contam. 30:1080-1086.

Rahman, M. M., and M. A. Samad. 2010. Prevalence of subclinical gastro-intestinal parasitosis and their effects on milk production with therapeutic management in red Chittagong cattle. Bangla. Soc. Vet. Med. 8:11-16.

Rose, M. D. C. Argent, G. Shearer, and W. H. H. Farrington. 1995a The effect of cooking on veterinary drug residues in food: 2 . Levamisole. Food Addit. Contam. 12:185-194.

Rose, M. D., J. Bygrave, W. H. H. Farrington, and G. Shearer. 1996 The effect of cooking on veterinary drug residues in food: 4 . Oxytetracycline clenbuterol. Food Addit. Contam. 13:275-286.

Rose, M. D., W. H. H. Farrington, and G. Shearer. 1995b The effect of cooking on veterinary drug residues in food: 3. Sulphametazine. Food Addit. Contam. 12:739-750.

Rose, M. D., G. Shearer, and W. H. H. Farrington. 1995c. The effect of cooking on veterinary drug residues in food: 1 . Clenbuterol. Food Addit. Contam. 12:67-76.

Sangster, N. C. 2001. Managing parasiticide resistance. Vet. Parasitol. 98:89-109.

Whelan, M., A. Furey, and M. Danaher. 2010. UPLC-MS/MS Method for the determination of triclabendazole residues in muscle. Page 208 in Proc. Sixth Int. Symp. Hormone and Veterinary Drug Residue Analysis, Ghent, Belgium. University of Ghent, Ghent, Belgium. 